\title{
CONSEQUÊNCIAS DA URBANIZAÇÃO NA VEGETAÇÃO E NA TEMPERATURA DA SUPERFÍCIE DE TERESINA - PIAUI
}

\author{
Sônia Maria Ribeiro Feitosa ${ }^{1}$; Jaíra Maria Alcobaça Gomes ${ }^{2}$; José Machado Moita Neto ${ }^{3}$;
} Carlos Sait Pereira de Andrade ${ }^{4}$

(recebido em 13.12.2010 e aceito para publicação em 08.07.2011)

\section{RESUMO}

Estudos que abordam a relação das áreas verdes com a urbanização são importantes, porque mostram a relação desses parâmetros com condições climáticas e qualidade de vida da população. Teresina vem se expandindo e perdendo parte da vegetação, condição importante na promoção de sombreamento e conforto térmico. Utilizou-se sensoriamento remoto e geoprocessamento de imagens do satélite Landsat 5, referentes aos dias 14/8/1989 e 9/11/2009, na análise da supressão da vegetação decorrente da expansão urbana em 20 anos e na formação do campo térmico para estimar a temperatura da superfície da área urbanizada. O objetivo geral é verificar a relação entre a expansão da cidade com a supressão da vegetação. Os objetivos específicos são identificar e quantificar a área vegetada e a urbanizada em 1989 e em 2009, identificando as mais aquecidas a partir da vegetação e da expansão urbana. Os resultados mostraram que a área urbanizada, em 1989, apresentava temperatura da superfície mais amena. Em 2009, com o crescimento da urbanização, as áreas verdes diminuíram, aumentando, assim, as áreas aquecidas. Diante das evidências, fazem-se necessárias ações de planejamento urbano capazes de reverter a diminuição de áreas verdes e seus efeitos na temperatura da superfície do solo e sobre a população.

Palavras-chave: Arborização; Clima urbano; Campo termal.

\footnotetext{
${ }^{1}$ Mestre do Programa de Pós-Graduação em Desenvolvimento e Meio Ambiente, PRODEMA/TROPEN/UFPI, Teresina - PI, Brasil, smrfeitosa@hotmail.com ${ }^{2}$ Professora Dra. do Departamento de Economia e do Programa de Pós-Graduação em Desenvolvimento e Meio Ambiente, PRODEMA/TROPEN/UFPI, Teresina - PI, Brasil, jaira@ufpi.edu.br ${ }^{3}$ Professor Dr. do Departamento de Química e do Programa de Pós-Graduação em Desenvolvimento e Meio Ambiente, PRODEMA/TROPEN/UFPI, Teresina - PI, Brasil, jmoita@ufpi.edu.br ${ }^{4}$ Professor Dr. do Departamento de Geografia e História e do Programa de Pós-Graduação em Geografia, CCHL/UFPI, Teresina - PI, Brasil, carlossait@yahoo.com.br
} 


\section{URBANIZATION CONSEQUENCES IN VEGETATION AND SURFACE TEMPERATURE OF TERESINA, PIAUI}

\section{ABSTRACT}

Studies about the relationship of green areas and urbanization are important because they show the relationship of these parameters with climatic conditions and quality of life. Teresina is expanding and losing part of vegetation, an important factor to promote shading and thermal comfort. We used remote sensing and GIS images from Landsat 5 satellite, referring to days 08/14/1989 and 09/11/2009, in assessment of vegetation removal due to urban expansion during 20 years and the formation of thermal field to estimated the surface temperature of urbanized area. Overall objective is to check the relationship between city expansion and vegetation removal. Specific objectives are identify and quantify urbanized and green area in 1989 and 2009, identifying the most heated areas resulting from the loss of vegetation and urban expansion. Results showed that urbanized area in 1989 had surface with mild temperature. In 2009, with the growth of urbanization, green areas decreased, thus increasing heated areas. In face of these evidences, urban planning actions are required to reverse the reduction of green areas and its effects on soil surface temperature and population.

Keywords: Afforestation; Urban climate; Thermal field.

\section{INTRODUÇÃO}

As transformações decorrentes do processo de crescimento da população e expansão urbana geram impactos no ambiente que são intensificados pelas constantes mudanças do espaço, causando um desequilíbrio na natureza e nas interações atmosferaTerra. O novo espaço construído, e constantemente modificado pelas variadas formas de ocupação do solo, altera os elementos meteorológicos, formando diferentes microclimas. Esses desequilíbrios são causados pela impermeabilização do solo, pelos materiais condutores de energia térmica utilizados no meio urbano, pela poluição do ar, pelo aumento das edificações e, principalmente, pela redução da vegetação.

Dentre as diversas transformações ocorridas no espaço urbano, a supressão da cobertura vegetal é uma das que contribui para alterar o clima da cidade, através de 
mudanças nos seus elementos meteorológicos. Monteiro (1976), Landsberg (1981), Mascaró (1996), Romero (2001) e Sorre (2006), ao discutirem as mudanças climáticas causadas pela urbanização, atribuem à própria cidade uma das responsabilidades pelo aquecimento, tendo como principal causa a substituição da vegetação por construções, que contribui para diminuir a umidade relativa do ar, devido à drenagem ou impermeabilização de áreas úmidas.

Uma das causas da formação de ilhas de calor na cidade, para Lombardo (1985), Oke (1987) e Coltriet al. (2007), são as mudanças dos fluxos de energia solar que chegam à superfície do solo através de processos físicos, alterando alguns elementos meteorológicos, em especial as temperaturas da superfície e do ar. Segundo os autores, maior aquecimento ocorre durante o dia, devido à capacidade térmica de absorção dos materiais de construção usados na cidade, que devolve parte da radiação recebida para a atmosfera.

O crescente processo de urbanização verificado nas cidades contribui para as alterações observadas no clima, em especial em áreas pouco arborizadas e com maior densidade de construções. Estudos como os de Souza Júnior (2006) em Campina Grande PB, Barbirato, Souza e Torres (2007) em Maceió - AL, Moura, Zanella e Sales (2008) em Fortaleza - CE, Viana e Amorim (2008) em Teodoro Sampaio - SP, Blain, Picoli e Lulu (2009) em três cidades de São Paulo, Xavier et. al. (2009) em Cuiabá - MT, indicaram que tanto a temperatura da superfície quanto a do ar, passaram por alterações ao longo do processo de expansão urbana.

Cavalheiro et al. (1999) conceituam áreas verdes como espaços livres onde o elemento fundamental de composição é a vegetação, tendo no mínimo 70,0\% em solo permeável (sem laje) e função ecológico-ambiental, estética e de lazer. Outros autores, como Mazzeiet al. (2007), Troppmair e Galina (2003) e Rosset (2005) discorrem sobre as mais diversas conceituações de áreas verdes, sem ainda uma definição consensual.

Nas cidades, a redução de áreas verdes e as superfícies modificadas do solo com elevada condutividade térmica absorvem maior quantidade de radiação solar, a ponto de, no cômputo final, gerar diferenças de temperatura superiores a $10,0^{\circ} \mathrm{C}$ entre a cidade e campo. Na zona rural ou nas periferias das metrópoles, geralmente há mais água disponível para a evaporação por existir maior quantidade de vegetação e áreas permeáveis, ao contrário dos centros urbanos, onde as construções e ruas pavimentadas fazem escoar a água, que poderia ser infiltrada e servir como reserva natural para a evaporação (RITTER, 2009).

A arborização é parâmetro importante na promoção de conforto e melhor qualidade de vida principalmente no meio urbano, cujas construções passam a agredir as paisagens, modificando o clima da cidade. Dantas e Souza (2004) encontraram deficiência de 
arborização em Campina Grande - PB, que obteve somente 0,08 árvore por habitante, sem contabilizar as árvores de quintais e jardins de residências. Segundo eles, ainda que o número de árvores duplicasse, estaria muito longe do recomendado pela Organização das Nações Unidas para a Educação, a Ciência e a Cultura (UNESCO), que é de duas árvores por habitante ou 12,0 $\mathrm{m}^{2} / \mathrm{hab}$. Ressalte-se, entretanto, que essa recomendação é controversa entre pesquisadores.

Em julho de 1977 foram observadas mais de 50 ilhas de calor urbanas no norte e centro-oeste dos Estados Unidos da América (EUA), mostrando diferenças de temperatura de $2,6^{\circ} \mathrm{C}$ a $6,5^{\circ} \mathrm{C}$ entre a zona urbana e a rural. Matsonet al. (1978) justificaram o fato como decorrente do crescente aumento da urbanização nas cidades observadas, a exemplo de St. Louis, Baltimore e Washington, D.C.

No Brasil, o estudo de Lombardo (1985), voltado à pesquisa com ilhas de calor urbano, para identificar elementos de ocupação do solo e verificar o aumento da temperatura da superfície, com uso de imagens de satélites, relacionando esse aumento à urbanização, foi um dos primeiros a ser realizado.

Cunha, Rufino e Ideião (2009) pesquisaram a relação entre o aumento de temperatura da superfície do ar e o crescimento da cidade de Campina Grande - PB, tomando como base os produtos e técnicas do sensoriamento remoto e investigando as possíveis alterações no clima da região.

Coltriet al. (2007) detectaram, através de geoprocessamento de imagens do satélite, ilhas de calor em Piracicaba - SP, em estudo que concluiu ser a quantidade de área verde numa cidade, determinante na intensidade da ilha de calor. Os autores classificam como áreas verdes todo e qualquer vegetal, inclusive grama e pasto, tanto dos bairros quanto da área rural.

É notório pela gama de trabalhos nas cidades brasileiras que a redução de áreas verdes, oriunda da ocupação urbana, está modificando o clima das cidades, fato que também está acontecendo em Teresina.

Sales (2003), em estudo sobre a importância da arborização na zona urbana de Teresina, fez um levantamento do total de árvores existente na cidade onde afirma que, em 2002, possuía 13,0 $\mathrm{m}^{2}$ de áreas verdes por habitante, menos que o índice de áreas verdes de outras cidades, como João Pessoa - PB, com 39,0 $\mathrm{m}^{2}$. Segundo a autora, as áreas verdes em Teresina-PI são encontradas nas varandas das residências, como espaço de trabalho nos bares e restaurantes, como proteção para carros nas ruas, e como abrigo em ponto de ônibus, entre muitas outras formas de utilização. As margens dos rios Poti e Parnaíba são utilizadas na prática do lazer e esportes, bem como os parques ambientais.

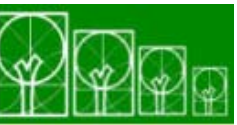

S · B $\cdot \mathbf{A} \cdot \mathbf{U}$ Soc. Bras. de Arborização Urbana 
Das 18 reservas denominadas "parques ambientais" existentes no perímetro urbano de Teresina, a maioria está localizada nas zonas Norte e Leste da cidade (TERESINA, 2010). Machado et al. (2010) encontraram um total de $105,4 \mathrm{~km}^{2}$ de áreas verdes, onde pode ser encontrada grande diversidade de árvores nativas, que também são encontradas em praças e ruas da cidade. Desse total, $31,6 \mathrm{~km}^{2}$ estão na zona Leste e $30,5 \mathrm{Km}^{2}$ na zona Centro-norte.

Teresina é uma cidade com altas temperaturas do ar, e ao longo do tempo vem se expandindo e perdendo parte de sua vegetação, condição importante na promoção de sombreamento, conforto térmico e manutenção da umidade relativa do ar. Assim, diante da carência de trabalhos que verifiquem a influência da urbanização na supressão da vegetação e na temperatura da superfície de Teresina - PI buscou-se uma resposta que justifique essas alterações, através da quantificação do total de áreas verdes na cidade.

As áreas urbanizadas e as vegetadas foram identificadas e quantificadas por meio da técnica de sensoriamento remoto e geoprocessamento de imagens da área urbana captadas pelo satélite Landsat5, referentes aos dias 14/8/1989 e 9/11/2009. A temperatura da superfície do solo foi estimada pela construção do campo térmico da área urbana utilizando-se essa mesma técnica.

O presente estudo aborda a relação da urbanização com o processo de supressão das áreas verdes na cidade de Teresina - PI ao longo de 20 anos, tendo-se como objetivo geral verificar a relação existente entre o processo de expansão da cidade com a supressão da vegetação. Os objetivos específicos foram detectar e quantificar a área vegetada e a área urbanizada em 1989 e em 2009 e identificar as áreas mais aquecidas da cidade a partir da quantidade de vegetação existente, da expansão urbana e das formas de ocupação do solo.

\section{MATERIAL E MÉTODOS}

Teresina, capital do Piauí, está localizada na região Norte do estado, situado no Nordeste do Brasil. A sede do município tem coordenadas geográficas $05^{\circ} 05^{\prime \prime}$ de latitude Sul e $42^{\circ} 48^{\prime \prime}$ de longitude Oeste e possui altitude média de 74,4 m acima do nível médio do mar. O clima é caracterizado como subúmido seco, megatérmico, com excedente hídrico moderado no verão. No trimestre setembro-outubro-novembro, a concentração da evapotranspiração potencial é de 32,1\% (BASTOS e ANDRADE JÚNIOR, 2008). 
Foram escolhidos fatores demográficos como contributivos para a redução das áreas verdes e aumento da temperatura da superfície de Teresina, pelo fato de o crescimento populacional incidir em práticas de consumo e de atividades que alteram o clima local.

O nível de urbanização foi verificado pela quantificação das áreas ocupadas por construções e por solos expostos e o Índice de Áreas Verdes (IAV) foi representado por todo tipo de vegetação encontrado no perímetro urbano de Teresina - PI, em 1989 e em 2009. Utilizou-se técnica de sensoriamento remoto a partir de uma imagem de satélite Landsat- 5 do dia 14/8/1989, e outra de 9/11/2009, ambas disponibilizadas pelo Instituto de Pesquisas Espaciais (INPE, 2010a).

A correção de ajustes de imagens por meio do software SPRING 4.3.3, seguida de realce e contraste, permitiu visualizar e classificar os elementos urbanos, que correspondem à vegetação, solos expostos, água e áreas construídas encontrados nas imagens captadas, enfatizando-se a extensão de área arborizada e área construída do sítio urbano. 0 comparativo entre as duas imagens possibilitou identificar a dinâmica espaço-temporal das áreas arborizadas e urbanizadas em 20 anos, determinando, quantitativamente, suas áreas respectivas, nos anos de 1989 e 2009.

Utilizou-se, para o cálculo do Índice de Áreas Verdes (IAV), a fórmula adotada por Harder (2002), dada pela soma de todas as áreas verdes dividida pela população referente à área de estudo, cuja expressão é:

\section{$I A V=T o t a l$ de áreas verdes/População}

Os termos "áreas verdes", "cobertura vegetal" e "arborização", usados no texto, representam a vegetação visualizada nas imagens de satélite LANDSAT 5, fato que pode resultar diferente resultado se comparado a outros índices calculados a partir de outros critérios de classificação.

Em seguida, o albedo das superfícies representado pela refletância, nas imagens, foi convertido em temperatura aparente da superfície com medidas obtidas através de sensor termal que fornece a temperatura da superfície, pelo software IDRISI, permitindo a visualização das áreas de temperatura superficial mais elevada. 


\section{RESULTADOS E DISCUSSÃO}

Teresina, desde os anos 1950, com a expansãodo setor de serviços, que crescia em ritmo acelerado, foi promovida a principal centro urbano do estado, condição essa, que,subsidiada pela política habitacional do governo, acelerou o processo de urbanização da cidade, como argumentam Façanha (1998) e Lima (2003).

De 1960 a 1980, como se pode observar na Tabela 1, a taxa de crescimento da população urbana de Teresina apresentou-se em contínuo crescimento.Em 2007, com um total de 779.939 habitantes (IBGE, 2007), a zona urbana de Teresina já atingia 94,3 \% da população total do município. Uma concentração populacional assim atua tanto como modificador do espaço físico, quanto das variantes sociais, econômicas e ambientais.

Tabela 1 - Evolução da população total e taxa de urbanização de Teresina no período de 1960 a 2010.

Table 1 - Evolution of total population and urbanization rate of Teresina in 1960 to 2010 period.

\begin{tabular}{ccc}
\hline Ano & $\begin{array}{c}\text { População total } \\
\text { (hab) }\end{array}$ & $\begin{array}{c}\text { Taxa de urbanização } \\
\text { (\%) }\end{array}$ \\
\hline 1960 & 142.691 & 68,9 \\
1980 & 377.774 & 89,8 \\
2007 & 779.939 & 94,3 \\
2010 & 802.537 & 94,3 \\
\hline & & Fonte:IBGE(2000; 2007; 2010). \\
& & Source: IBGE (2000; 2007; 2010).
\end{tabular}

Apesar de o ritmo de crescimento populacional de Teresina ter diminuído a partir dos anos 1990, em 2010, a população total já representa 21,6 \% da população do Piauí, que é de 3.119.015habitantes (IBGE, 2010). Como polo de convergência de municípios e estados vizinhos, gera fatores antrópicos que, ao longo do tempo, foram alterando alguns elementos meteorológicos, principalmente os relacionados com o aquecimento do solo e do ar. $\mathrm{Na}$ verdade, a concentração populacional em centros urbanos e, consequentemente o fluxo de pessoas que diariamente circulam na cidade em busca de produtos e serviços, aumentam as atividades que geram microclimas urbanos (MONTEIRO, 1976; LOMBARDO, 1985; ROMERO, 2001). 
É importante observar que nos últimos dez anos a população de Teresina cresceu $12,2 \%$, taxa elevada em relações a outros centros urbanos, o que aponta para uma tendência de continuidade de redução de áreas verdes na cidade.

Mesmo com a preocupação em relaçãoà prática do desmatamento, para dar lugar às construções promovidas pela expansão populacional, percebe-se que todos os estudos que tratam da arborização na cidade de Teresina, ainda a destacam como detentora de quantidade razoável de áreas verdes. Entretanto, também já demonstram preocupação com a crescente perda dessas áreas, em favor do ambiente construído.

A técnica de sensoriamento remoto permitiu identificar e quantificar as áreas urbanizadas e as vegetadas na cidade de Teresina - PI a partir de duas imagens de satélite Landsat 5. Como é demonstrada na FIGURA 1, uma cena do perímetro urbano da cidade, captada no dia 14/8/1989 (a), e a uma imagem classificada destacando os elementos selecionados encontrados na área selecionada (b).

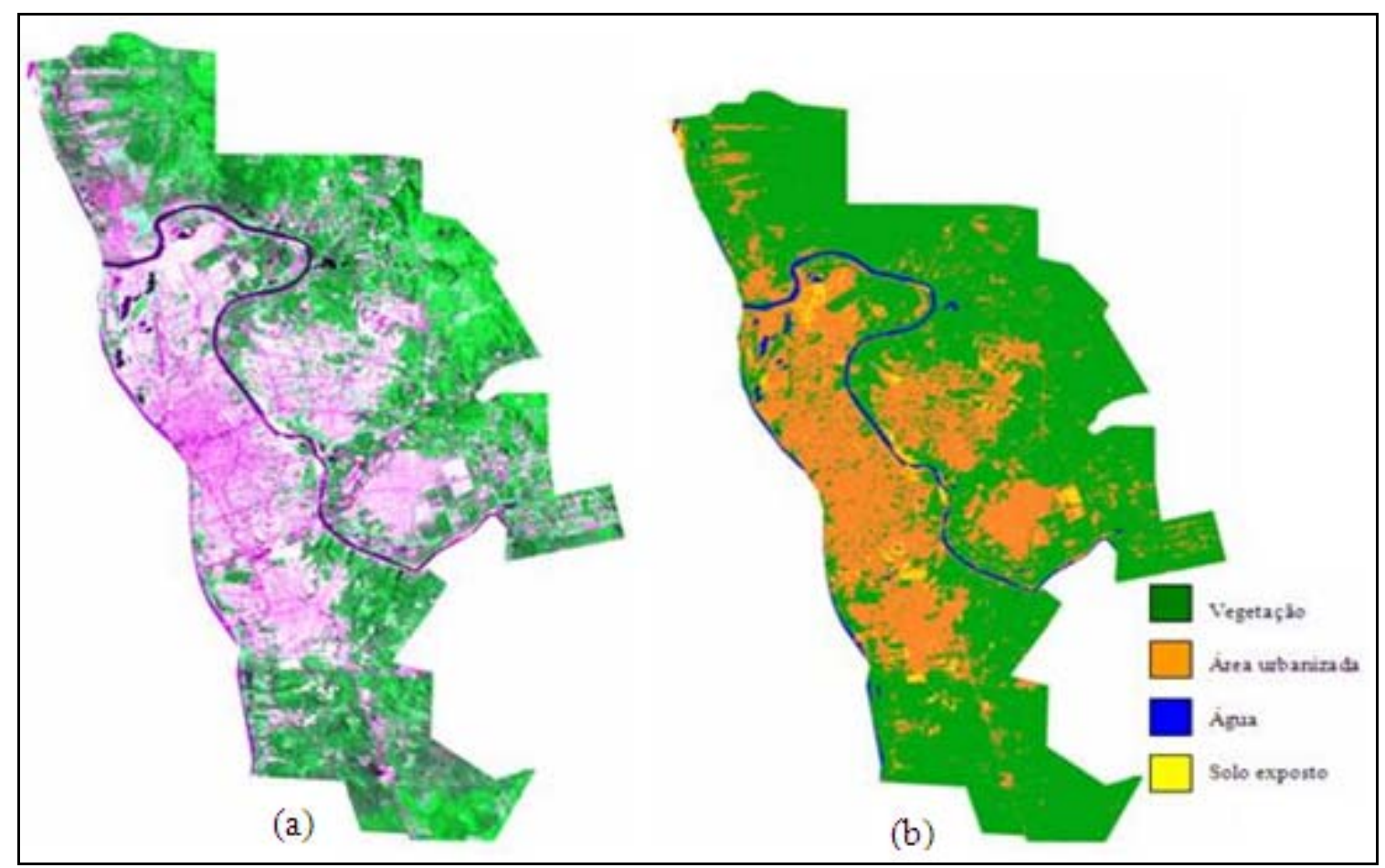

Fonte: A partir de imagens do satélite Landsat5 disponibilizadas pelo INPE(2010a). Source: From Landsat 5 satellite images released by INPE (2010a).

Figura 1 - Imagem do sítio urbano de Teresina captada no dia 14/8/1989 pelo satélite Landsat 5 [composição colorida do perímetro urbano (a) e imagem classificada (b)].

Figure 1 - Image of Teresina urban area captured in 8/14/1989 by Landsat 5 [color composition of urban perimeter (a) and classified image (b)]. 
A cena representa o dia 14/8/1989 considerado menos urbanizado, quando Teresina ainda conservava maior quantidade de áreas verdes, como pode ser observado, pela quantidade de área urbanizada e área construída, no período analisado.

O processo de expansão de áreas urbanizadas e desmatadas pode ser visualizado na Figura 2 que corresponde a uma cena captada no dia 9/11/2009, em Teresina, quando a urbanização na cidade já se encontrava em nível elevado, com 113,9 km² de área urbanizada.

À medida que Teresina se expandia, aumentava o desmatamento cedendo lugar às áreas construídas. Também aumentaram as áreas de solos expostos, provavelmente destinadas a loteamentos, que possuem maior albedo, em relação a qualquer tipo de vegetação.

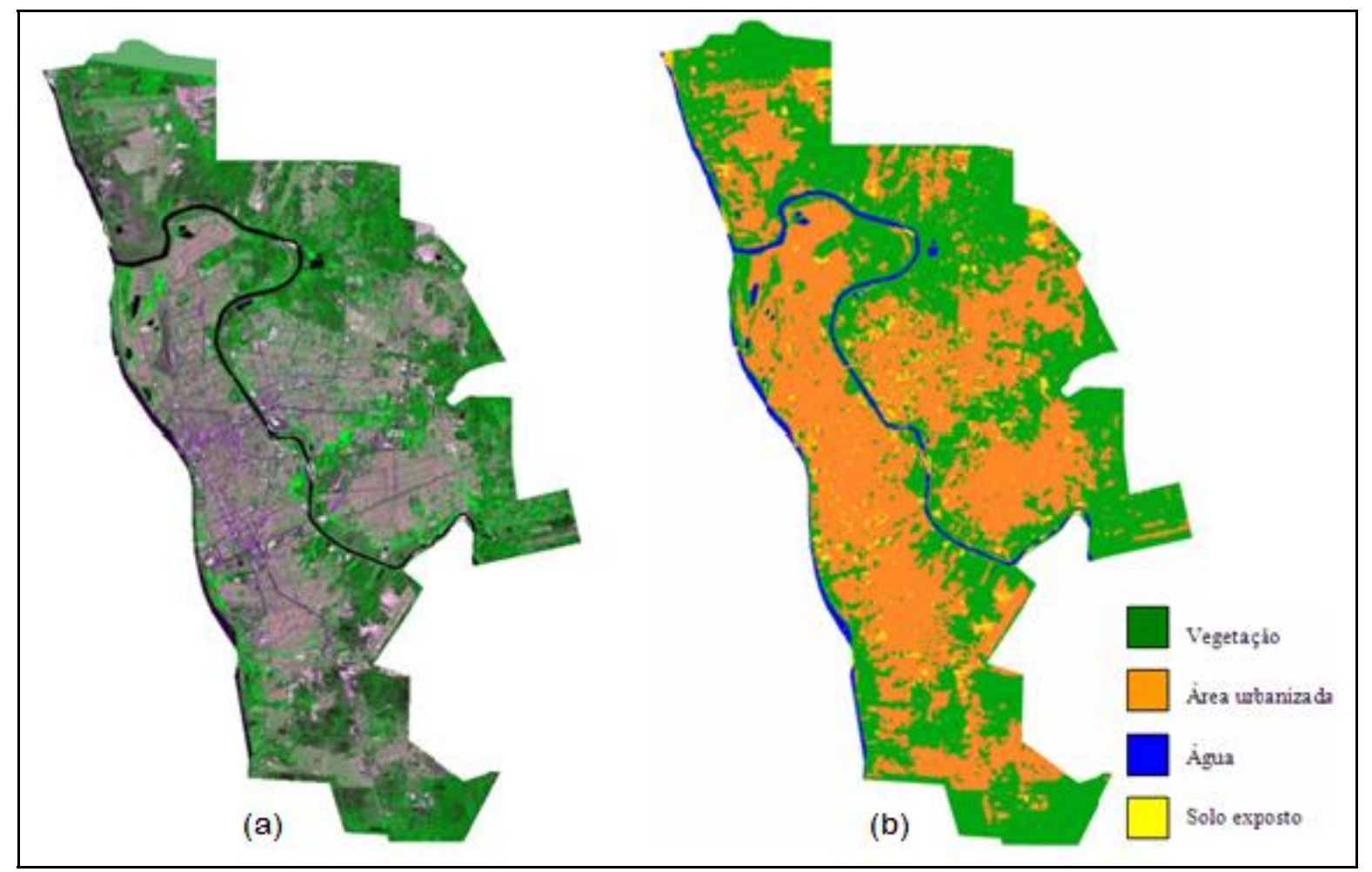

Fonte: A partir de imagens do satélite Landsat5 disponibilizadas por INPE (2010 a). Source: From Landsat 5 satellite images released by INPE (2010 a).

Figura 2 - Imagem do sítio urbano de Teresina captada no dia 9/11/2009 pelo satélite Landsat 5 [composição colorida do perímetro urbano (a) e imagem classificada (b)].

Figure 2 - Image of Teresina urban area captured in 11/9/2009 by Landsat 5 [color composition of urban perimeter (a) and classified image (b)].

A classificação da imagem permitiu visualizar que em 1989, Teresina dispunha de maior quantidade de áreas verdes que no ano de 2009, quando grande parcela dessa (4) $\Rightarrow$ क 
vegetação passa a ser substituída por construções ou solos expostos ou desnudos. O curso dessa urbanização estendeu-se, principalmente, para as zonas Leste e Sul, uma vez que a região central da cidade já se apresentava densamente construída.

Para melhor compreensão do processo evolutivo da urbanização da cidade, a Tabela 2 apresenta as áreas dos objetos urbanos de interesse no estudo, detectados pelo satélite Landsat 5 e classificados a partir de georeferenciamento das imagens.

Tabela 2 - Classificação e quantificação de elementos ambientais presentes no perímetro urbano de Teresina em 1989 e 2009.

Table 2 - Classification and quantification of environmental elements present in Teresina urban area in 1989 and 2009.

\begin{tabular}{|c|c|c|}
\hline \multirow{2}{*}{$\begin{array}{l}\text { Classificação de elementos que } \\
\text { compõem o perímetro urbano de } \\
\text { Teresina - PI }\end{array}$} & \multicolumn{2}{|c|}{ Área $\left(\mathbf{k m}^{2}\right)$} \\
\hline & 1989 & 2009 \\
\hline Veqetacão & 162.7 & 114.4 \\
\hline Urbanizacão & 71.0 & 113.9 \\
\hline Solo exposto/areia & 5.3 & 9.3 \\
\hline Áqua & 4.6 & 6.0 \\
\hline Fonte: Dados bás & $\begin{array}{c}243,6 \\
\text { ficados a p } \\
5 \text { disponibi }\end{array}$ & $\begin{array}{l}243,6 \\
\text { de satélite } \\
\text { E (2010a) }\end{array}$ \\
\hline
\end{tabular}

Atribui-se o fato de a área de superfícies de água ter aumentado $1,4 \mathrm{~km}^{2}$, dentre algumas razões, ao assoreamento dos rios provocado pela ação humana o que fez aumentar o espelho de água, à impermeabilização do solo que impede o escoamento da água e ao aumento do número de piscinas entre 1989 e 2009. O banco de dados de precipitação (Embrapa Meio-Norte, 2010) registra que os 12 meses compreendidos de agosto de 1988 a julho de 1989, que antecederam o dia analisado na imagem (14/8/1989), acumularam 1.643,8 mm de precipitação pluviométrica, enquanto os 12 meses de novembro de 2008 a outubro de 2009 que antecederam o dia da imagem analisada em 2009 (19/11/2009) acumularam 2.015,5 mm. O maior total acumulado de chuvas pode ter influenciado, tanto reduzindo a temperatura da superfície em 2009 quanto para aumentar as superfícies de água dos rios e reservatórios.

Outro parâmetro que contribuiu para que a área de água se apresentasse maior em 2009, foi o fato de o início da estação chuvosa na região Sul do Piauí,dá-se em outubro, fazendo com que em novembro, quando foi capturada a imagem de satélite, o nível do rio (4) $\Rightarrow$ 
Parnaíba estivesse mais elevado em relação a 1989, cuja imagem era de agosto, mês sem chuvas em todo o estado.

Todos esses fatores podem ter contribuído para alterar a temperatura da superfície, podendo, ainda, ser acrescentada a margem de erro do satélite e dos softwares operados nos procedimentos com as imagens utilizadas no estudo.

Houve, entre os dois períodos analisados, redução na densidade de áreas verdes e aumento de áreas urbanizadas e de solos expostos na cidade de Teresina. A área ocupada aumentou, em $2009,60,4$, em relação a 1989 , atingindo $113,9 \mathrm{~km}^{2}$, enquanto a vegetação foi suprimida. Vale salientar que o aplicativo usado na classificação dos objetos visualizados nas imagens, pelo satélite, considera algumas áreas com alto poder de refletividade, como se fosse solo exposto, devido ao albedo da superfície. Entre 1989 e 2009, o perímetro urbano de Teresina perdeu 29,7\% de sua vegetação, demonstrando serem necessárias medidas técnicas e administrativas direcionadas às políticas que minimizem as alterações ambientais.

De acordo com os dados obtidos pelas imagens de satélites e com a metodologia adotada neste estudo para o cálculo do Índice de Área Verde, tem-se que em Teresina, em 1989, para a população referente ao ano de 1991 o IAV $=271,5 \mathrm{~m}^{2} / \mathrm{hab}$., sendo reduzido para 140,4 $\mathrm{m}^{2} / \mathrm{hab}$., em 2010. Este valor é muito superior aos $13 \mathrm{~m}^{2} / \mathrm{hab}$., citado por Sales (2003), mas, próximo do valor encontrado por Machado et al. (2010), em 2000, que foi de $141,2 \mathrm{~m}^{2} /$ hab e em 2006 de 112,4 $\mathrm{m}^{2} / \mathrm{hab}$, cuja diferença entre valores, possivelmente se deve às diversas terminologias usadas para "áreas verdes" e ainda às metodologias adotadas no cálculo do índice de áreas verdes.

Independentemente das terminologias ou técnicas adotadas para o cálculo do IAV, foi constatado que à medida que a população aumentou, o IAV da cidade diminuiu, indicando necessidade de estudos mais aprofundados que analisem a influência da supressão da vegetação na temperatura do ar do local e um melhor embasamento sobre a temática, com uma discussão mais abrangente acerca do IAV de Teresina - PI a partir de literaturas afins e de resultados de campo validados.

O processo de urbanização de uma cidade, acompanhado da perda de vegetação, é parâmetro relevante para a definição da temperatura da superfície do local, como se pode observar na análise dos elementos urbanos visualizados nas imagens referentes aos dias 14/8/1989 e 9/11/2009 que mostram efetiva relação da urbanização com a temperatura da superfície do solo de Teresina - PI.

A FIGURA 3 apresenta o campo térmico da cidade de Teresina - PI, a partir do geoprocessamento de imagens captadas pelo satélite Landsat 5 nos dias 14/8/1989 e 
9/11/2009. Quanto maior a capacidade de absorção de calor das superfícies receptoras, maior o índice de refletância e maior também a temperatura da superfície, que depende da forma de ocupação do solo e do material utilizado nas diversas modalidades de ocupação.

$\mathrm{Na}$ FIGURA $3 \mathrm{a}$ e b, as faixas em tonalidade verde correspondem às áreas vegetadas e, consequentemente dotadas de temperaturas mais baixas. As em tons laranja e vermelho equivalem às temperaturas das áreas com maior retenção de calor, que coincidem com as urbanizadas ou descampadas. As diferenças de temperatura da superfície entre a região periférica e o centro urbano podem ser observadas nas imagens do campo térmico referentes aos anos de 1989 e 2009.

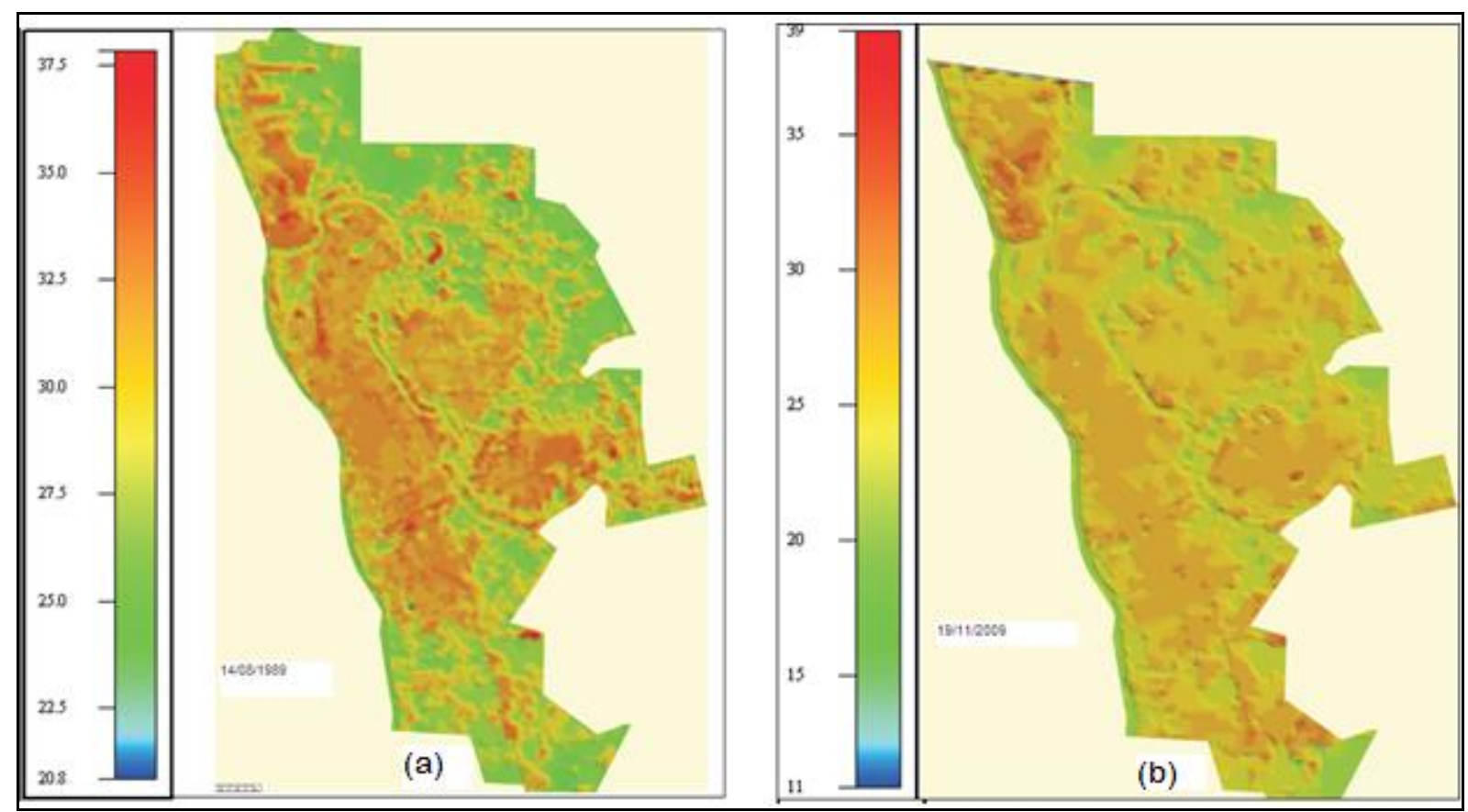

Fonte: A partir de imagens do satélite Landsat5 disponibilizadas por INPE (2010a). Source: From Landsat 5 satellite images released by INPE (2010a).

Figura 3 - Imagem do campo termal da cidade de Teresina transformada em temperatura aparente da superfície do solo no dia 14/8/1989 (a) e 9/11/2009 (b), a partir do satélite Landsat 5 , banda 6 .

Figure 3 - Image of Teresina thermal field transformed into apparent temperature of soil surface in 08/14/1989 (a) and 11/9/2009 (b) from Landsat 5, band 6.

As temperaturas estavam em 1989 e 2009, altas, em especial na região central da cidade, onde se concentram aglomerados de construções com materiais refletivos e reduzido índice de arborização. Neste estudo, atribuiu-se às áreas livres de vegetação e de construção,a denominação de solos expostos ou áreas descampadas. 
Em 2009, com a continuidade do crescimento, parte das áreas antes arborizadas foi substituída por áreas construídas, havendo algumas, na zona Norte e na zona Sudeste, que eram, em 1989, loteamentos descampados, com maior capacidade de refletância, o que fez com que o albedo se apresentasse maior naquele ano.

A FIGURA 3a mostra o campo térmico do dia 14/8/1989, quando a população de Teresina era de 599.272 habitantes. A temperatura máxima do ar, observada nesse dia, foi de $34,0^{\circ} \mathrm{C}$, enquanto a da superfície, próximo das $12 \mathrm{~h}$ local, horário da passagem do satélite em Teresina, esteve entre $25,0^{\circ} \mathrm{C}$ a 37,0 ${ }^{\circ} \mathrm{C}$. Na imagem do dia 9/11/2009, a temperatura da superfície mostra-se variando entre $22,0{ }^{\circ} \mathrm{C}$ e $39,0{ }^{\circ} \mathrm{C}$, enquanto a temperatura máxima do ar, registrada na estação meteorológica da Embrapa Meio-Norte (2010) foi de $37,6^{\circ} \mathrm{C}$.

O campo termal das duas imagens indica que a temperatura da superfície é menor na periferia, o que deve relacionar-se com a quantidade de áreas verdes existentes. Em 2009, quando a quantidade dessas áreas em Teresina apresentou-se reduzida em relação a 1989, aumentaram também as áreas onde se concentram as temperaturas mais elevadas. Tanto em 1989 quanto em 2009 as temperaturas da superfície são mais altas nas regiões com pouca vegetação.

Em 2009, houve um aumento de áreas com temperaturas da superfície mais elevadas que a periferia, em relação a 1989, representada pelo aumento do albedo das superfícies, constatação que evidencia a relação entre ilhas de calor e sua intensidade com a quantidade de áreas verdes.

As condições meteorológicas apresentadas na FIGURA 4 a e b, imagens dos satélites meteorológicos GOES 7 e GOES 10, referentes aos dias 14/8/1989 e 9/11/2009, disponibilizadas pelo INPE (2010b) evidenciam que nos horários de sua captação havia pouca nebulosidade e baixa umidade relativa do ar. Nos dois dias, de acordo com dados da Embrapa Meio-Norte (2010), a insolação foi, respectivamente, de 10,3 horas e 11,2 horas de brilho solar e umidade relativa do ar de 54,0 \% e 51,0 \%. 


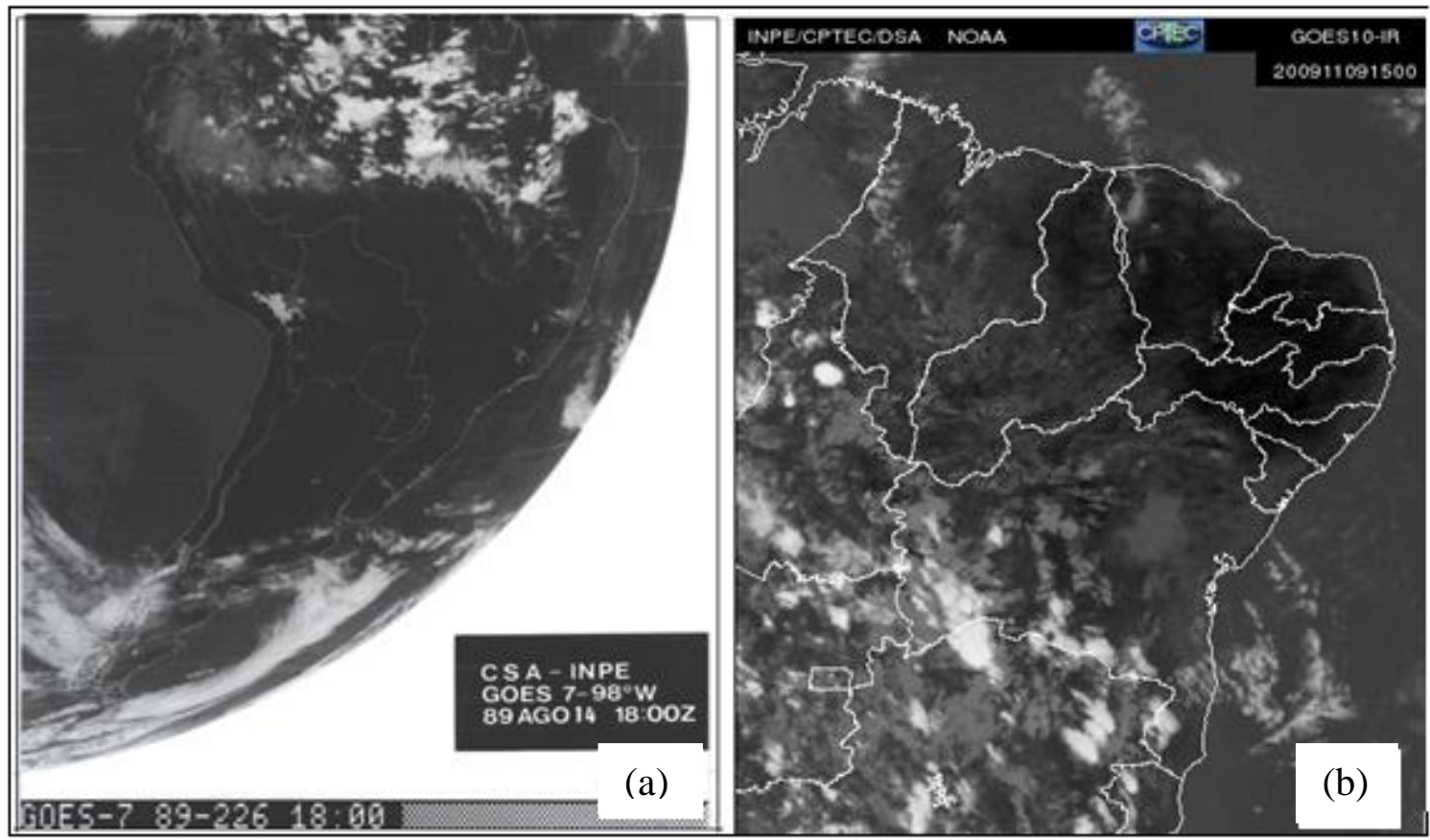

Fonte: INPE (2010b). Source: INPE (2010b).

Figura 4 - Imagem de satélite GOES 7 referente ao dia 14/8/1989 às 18:00 TMG ou 15:00 h local (a) e imagem do satélite GOES 10 referente ao dia 9/11/2009 às 15:00 $\mathrm{TMG}^{1}$ ou 12:00 h local (b).

- TMG (Tempo Médio de Greenwich) corresponde ao fuso horário de referência a partir do qual se calculam todas as outras zonas horárias do mundo. O TMG possui três horas a mais que a hora local (hora de Brasília).

Figure 4 - Image from 7 GOES Satellite in 8/14/1989 at 18:00 GMT (a) or 3:00 p.m local time and from GOES 10 satellite in 11/9/2009 at 15:00 GMT or 12:00 a.m. (b)

- GMT (Greenwich Mean Time) corresponds to the time zone of reference from which all other time zones around the world are calculated. GMT has more three hours than local time (Brasília time).

Os dois dias apresentaram condições favoráveis à ocorrência de temperaturas elevadas, entretanto, o resultado encontrado através das imagens do campo térmico (FIGURA 3) não mostra grande diferença de temperatura da superfície entre as duas cenas (imagens $3 a$ e $3 b$ ). Inclusive, em 2009, aparentemente a temperatura da superfície mostrouse menor que em 2009, o que provavelmente se deve ao fato de no mês de novembro já ter sidoregistradas algumas chuvas, apesar do baixo total acumulado até 9/11/2009. Outra justificativa pode ser atribuída à capacidade de operação técnica do satélite e seus sensores, que foi modificada no intervalo de tempo de vinte anos, entre a primeira e segunda imagem. 


\section{CONCLUSÕES}

Os resultados do estudo apontaram que em 20 anos as áreas vegetadas em Teresina diminuíram ao tempo em que a população cresceu e a cidade se expandiu, verificando-se temperatura da superfície do solo mais elevada nas regiões de maior concentração de áreas construídas. Nas periferias, onde há maior índice de áreas verdes, as temperaturas são mais amenas.

A maior expansão de áreas de superfícies aquecidas em 2009, quando comparadas ao ano de 1989, indica que essa situação pode influenciar o aumento da temperatura do ar e alterar o comportamento do clima. Esse fato sugere a adoção de políticas que minimizem os efeitos provocados pelas atividades urbanas, tendo como meta principal a conservação de áreas vegetadas e de reservatórios de água que contribuem para a manutenção da umidade do ar, como forma de reduzir os efeitos causados pelas mudanças no clima e proporcionar melhor conforto à população.

\section{REFERÊNCIAS BIBLIOGRÁFICAS}

BARBIRATO, G. M; SOUZA, L. C. L.; TORRES, S. C. Clima e cidade: a abordagem climática como subsídio para estudos urbanos. Maceió: EDUFAL, 2007.

BASTOS, A. E.; ANDRADE JÚNIOR, A. S. de. Boletim agrometeorológico de 2007 para o Município de Teresina, PI. Teresina: Embrapa Meio-Norte, 2008.

BLAIN,G. C.; PICOLI, M. C. A.; LULU, J. Análises estatísticas das tendências de elevação nas séries anuais de temperatura mínima do ar no estado de São Paulo.Bragantia, Campinas, v.68, n.3, p.807, 2009.

CAVALHEIRO, F; NUCCI, J.C; GUZZO, P; ROCHA, Y.T. Proposição de Terminologia para o Verde Urbano.Boletim Informativo da Sociedade Brasileira de Arborização Urbana. SBAU: v. 7, n.3, 1999. Rio de Janeiro, RJ, 1999.

COLTRI, P. P.; FAGNANI, M. A.; LABAKI, L. C.; FERREIRA, N. J.; DEMÉTRIO, V. A. Variabilidade dos principais elementos climáticos e urbanização na região de Piracicaba (SP). BioEng, Campinas, v.1, n.2, p.197-208, 2007. 
CUNHA, J. E. B. L.; RUFINO, I. A. A.; IDEIÃO, S. M. A. Determinação da temperatura de superfície na cidade de Campina Grande-PB a partir de imagens do satélite Landsat 5-TM. In: SIMPÓSIO BRASILEIRO DE SENSORIAMENTO REMOTO, 14, 2009. Natal. Anais... Natal,: INPE, 2009, p. 5717-5724.

DANTAS, I. C.; SOUZA, M. C. Arborização urbana na cidade de Campina Grande-PB: inventário e suas espécies. Revista de Biologia e Ciência da Terra (Bioterra), Campina Grande, v. 4, n. 2, 2004.

EMPRESA BRASILEIRA DE PESQUISA AGROPECUÁRIA (Embrapa Meio-Norte). Série de dados meteorológicos de Teresina - PI referentes ao período 1977 a 2009. Estação Meteorológica Convencional da EMBRAPA - Meio Norte. Teresina, 2010.

FAÇANHA, A. C. Evolução urbana de Teresina: agentes, processos e formas espaciais da cidade. 1998. Dissertação (Mestrado em Geografia). Universidade Federal de Pernambuco, 1998.

HARDER, I. C. F. Inventário Quali-Quantitativo da Arborização e Infra-Estrutura das Praças da cidade de Vinhedo (SP).Dissertação (Mestrado). Escola Superior de Agricultura Luiz de Queiroz. Piracicaba, SP, 2002.

IBGE. INSTITUTO BRASILEIRO DE GEOGRAFIA E ESTATÍSTICA.Censos demográficos de 1960 a 2000.2000.Disponível em: < http://www.ibge.org.br>. Acesso em: 20 dez. 2010.

IBGE. INSTITUTO BRASILEIRO DE GEOGRAFIA E ESTATÍSTICA. Contagem da população 2007. 2007. Disponível em:< http://www.ibge.org.br >. Acesso em: 20 dez. 2010. IBGE. INSTITUTO BRASILEIRO DE GEOGRAFIA E ESTATÍSTICA.Primeiros Resultados do Censo 2010. 2010. Disponível em: < http://www.ibge.org.br >. Acesso em: 11 dez. 2010. INPE. INSTITUTO DE PESQUISAS ESPACIAIS.Imagens de satélite do dia 14/08/1989 e do dia 09/11/2009. Catálogo de imagens. Disponível em: <www.inpe.br>. Acesso em: 3 fev. 2010a.

INPE. INSTITUTO DE PESQUISAS ESPACIAIS. Imagem de satélite Goes7 do dia 14/08/1989 às 18: 00 TMG e imagem do satélite GOES 10 do dia 09/11/2009 às 15: 00 TMG. Re: Imagens.[mensagem pessoal]. Mensagem recebida por <smrfeitosa@hotmail.com> em 24 mar.2010b. 
LANDSBERG, H. E. The urban climate.New York: Academic Press, 1981.285p.

LIMA, A. J. As Multifaces da pobreza: formas de vida e representações simbólicas dos pobres urbanos. Teresina: Halley, 2003.

LOMBARDO, M. A. Ilhas de calor nas metrópoles: o exemplo de São Paulo. São Paulo: Hucitec,1985.

MACHADO, R. R. B.; PEREIRA, E. C.G.; ANDRADE, L. H.C. Evolução temporal (20002006) da cobertura vegetal na zona urbana do município de Teresina - Piauí - Brasil. REVSBAU. Piracicaba, SP. v.5, n.3, p.97-112, 2010.

MASCARÓ, L. Urbanenvironment. Porto Alegre: Sagra, DC Luzzatto, 1996.

MATSON, M. E.; MCCLAIN, P. D.; MCGINNIS JÚNIOR, F.; PRITCHARD, J. A. Satellite Detection of Urban Heat Islands. NOAA/National Environmental Satellite Service, Washington, DC 20233,1978.

MAZZEI, K.; COLSESANTI, M.T.M.; SANTOS, D.G. Áreas verdes urbanas, espaços livres para o lazer. Sociedade e Natureza, Uberlândia, MG, v.19, n.1. p 33-43, 2007.

MONTEIRO, C. A de F. Teoria e clima urbano. IGEG-USP. Universidade de São Paulo. Instituto de Geociências. n. 25, São Paulo, 1976.

MOURA, M. O; ZANELLA, M. E; SALES, M. C. L. Ilhas térmicas na cidade de FortalezaCE.Boletim Goiano de Geografia. Goiânia, v.28, n.2, p. 33-34,2008

OKE,T. R. Boundary Layer Climates. 2ed. London: Routledge,1987.

RITTER, M. E. The Physical Environment: an Introduction to Physical Geography. Climate. Disponível em:<http://www.uwsp.edu/geo/faculty/ritter/geog101/textbook/climate_systems/urban_climat e.html >. Acesso em: 17 dez. 2009.

ROMERO, M. A. B. A arquitetura bioclimática do espaço público.ed. UNB. Coleção arquitetura e urbanismo: Brasília, 2001. 
ROSSET, F. Procedimentos metodológicos para estimativa do índice de áreas verdes públicas. Estudo de caso: Erechim, RS. São Carlos: UFSCar, 2005. Dissertação (Mestrado) Universidade Federal de São Carlos, 2005.

SALES, M. S. T. M. Educação Ambiental: a preservação do verde na zona urbana de Teresina. 2003. Dissertação (Mestrado em Desenvolvimento e Meio Ambiente) Universidade Federal do Piauí, UFPI. Teresina, 2003.

SORRE, M. Objeto e método da climatologia. Tradução de José Bueno Conti, FFLCH, USP. Original em francês: Traitè de climalogiebiologiqueetmedicle. Revista do Departamento de Geografia, n.18, p.89, 2006.

SOUSA JÚNIOR, I. F. de. A influência da urbanização no clima da cidade de Campina Grande-PB. Dissertação (Mestrado) Universidade Federal de Campina Grande. Campina Grande, 2006.

TERESINA. Perfil de Teresina: econômico, social, físico e demográfico. Secretaria Municipal de Desenvolvimento Econômico e Turismo. Teresina: SEMDEC, 2010.

TROPPMAIR, H; GALINA, M. H. Áreas Verdes. Território e Cidadania. Rio Claro, n. 2, 2003.

VIANA, S. S. M; AMORIM, M. C. C.T. Caracterização do clima urbano em Teodoro Sampaio - SP:uma introdução. Sociedade e Natureza. Uberlândia, v.20, n.2, 19-42, 2008.

XAVIER, A. L.; NOGUEIRA, M, C, J de.; MAITELLI, G, T.; OLIVEIRA A, G.; OLIVEIRA, A, S, de.; SANTOS, F, M, M.; NOGUEIRA, J, S. Variação de temperatura e umidade entre áreas urbanas de Cuiabá. Engenharia Ambiental. Espírito Santo do Pinhal. v.6, n.1, p.8293, 2009. 